\title{
Avaliação físico-química e composição centesimal de filés de peixe comercializados em Belém do Pará, Brasil
}

Avaliação físico-química e composição centesimal de filés de peixe comercializados em Belém do Pará, Brasil

\author{
F. C. Corrêa ${ }^{1}$; L. P. Santos ${ }^{2}$; F. E. R. Silva ${ }^{3}$; I. C. C. Barbosa ${ }^{4 *}$; R. M. S. Santa \\ Rosa $^{4}$
}

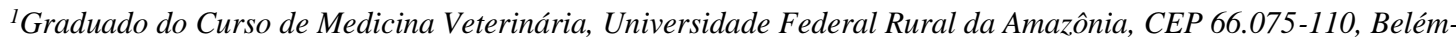
Pará, Brasil

${ }^{2}$ Técnica em Química do Instituto Socioambiental e dos Recursos Hídricos/Centro de Tecnologia Agropecuária, Universidade Federal Rural da Amazônia, CEP 66.077-830, Belém-Pará,Brasil.

${ }^{3}$ Docente do Instituto da Saúde e Proteção Animal, Universidade Federal Rural da Amazônia, CEP 66.077-830, Belém-Pará,Brasil.

${ }^{4}$ Docente do Instituto Socioambiental e dos Recursos Hídricos/Centro de Tecnologia Agropecuária, Universidade Federal Rural da Amazônia, CEP 66.077-830, Belém-Pará, Brasil.

*belemivan@hotmail.com

(Recebido em 18 de julho de 2016; aceito em 25 de outubro de 2016)

O objetivo do trabalho foi avaliar a qualidade físico-química de filés de espécies de peixes comercializados em feiras livres de Belém - PA e determinar a composição centesimal desses produtos. Foram realizadas análises físico-químicas (temperatura, $\mathrm{pH}$, cocção e prova de amônia), composição centesimal (umidade, proteínas, lipídeos, cinzas e carboidratos) e determinação de valor calórico de filés de 14 amostras das espécies de peixes dourada, filhote, piramutaba, pescada gó e pescada amarela. As análises foram realizadas segundo recomendações do Laboratório Nacional de Referência Animal e Instituto Adolfo Lutz. Os resultados de temperatura de conservação variaram de 10,9 a $22,7{ }^{\circ} \mathrm{C}$; os valores de $\mathrm{pH}$ variaram de 6,37 a 7,22; os resultados para cocção e amônia foram negativos. Na determinação da composição centesimal, a umidade variou de 78,80 a 85,45\%; proteína de 13,83 a 18,63\%; teor de lipídios de 0,08 a 1,44\%; teor de cinzas de 0,98 a 1,52\%; teor de carboidratos de 0,21 a $0,95 \%$ e os valores calóricos variaram entre 56,04 a 85,03 kcal/100g. Houve diferença estatística significativa entre as espécies de peixes para os parâmetros temperatura, $\mathrm{pH}$, umidade, proteínas e cinzas. Todas as amostras avaliadas estavam em desacordo com a legislação quanto à temperatura de conservação. Avaliando o valor de $\mathrm{pH}$, apenas as amostras de filhote atenderam ao preconizado na legislação. O estudo da composição centesimal revelou baixo teor de gordura e de valor calórico. É possível observar a influência das espécies e sua composição química pelos grupos formados na HCA (Análise de Agrupamento Hierárquico) e PCA (Análise de Componentes Principais).

Palavras-chave: valor nutricional, composição química, análise multivariada.

The objective of this study was to evaluate the physical and chemical quality of fillets of fish species sold in street markets of Belém-PA, and determine the chemical composition of these products. Were realized physical and chemical analysis (temperature, $\mathrm{pH}$, cooking and proof of ammonia), chemical composition (moisture, protein, lipid, ash and carbohydrates) and determination of calorific value of fillets to 14 samples of the species of fish: golden catfish, kumakuma, laulao catfish, king weakfish and acoupa weakfish. The analysis were performed according to the Laboratório Nacional de Referência Animal and the Instituto Adolfo Lutz. The results of conservation temperature ranged from 10.9 to $22.7^{\circ} \mathrm{C}$; $\mathrm{pH}$ values ranged from 6.37 to 7.22; the results of cooking and ammonia were negative. Moisture ranged from 78.80 to $85.45 \%$; protein from 13.83 to $18.63 \%$; lipid values ranged from 0.08 to $1.44 \%$; ash content from 0.98 to $1.52 \%$; carbohydrate from 0.21 to $0.95 \%$ and calories from 56.04 to $85.03 \mathrm{kcal} / 100 \mathrm{~g}$. There was a statistically significant difference between fish species for the parameters: temperature; $\mathrm{pH}$; moisture; protein and ash. All samples analyzed were in disagreement with the rules regarding the storage temperatures, while that $\mathrm{pH}$, only the kumakuma samples comply the recommended legislation. The study of the chemical composition showed low fat and calorie values, and observed the influence of the species on the chemical composition by HCA (Hierarchical Cluster Analysis) and PCA (Partial Components Analysis).

Keywords: nutritional value, chemical composition, multivariate analysis. 


\section{INTRODUÇÃO}

Peixe fresco é o produto oriundo de espécimes saudáveis e de qualidade adequada para o consumo humano sem ter sofrido qualquer processo de conservação. É conservado somente pelo resfriamento com gelo a uma temperatura próxima a do ponto de fusão da água [1].

A produção de peixe e seus derivados no mundo apresentou crescimento constante nas últimas cinco décadas, a uma taxa média anual de 3,2 \%, ultrapassando a taxa média de crescimento da população mundial, que foi de $1,6 \%$. Esses dados são concordantes com o aumento do consumo mundial médio de peixe por pessoa, que passou de 9,9 kg em 1960 para $17,0 \mathrm{~kg}$ na década de 2000 e $18,9 \mathrm{~kg}$ em 2010, resultado da combinação do crescimento populacional, aumento da renda e da forte expansão da produção de peixes [2].

No Brasil, de acordo com dados de 2014 do Ministério da Pesca e Aquicultura (MPA), o consumo nacional de peixes e seus derivados também vêm apresentando aumento significativo. Passou de 7 kg/ano por habitante em 2009 para 11,17 kg/ano nos anos de 2010 e 2011. Enquanto em 2013 o consumo médio foi de 14,5 kg/ano per capita, superando a meta da Organização Mundial de Saúde (OMS) de $12 \mathrm{~kg} /$ ano [3]. O consumo de peixe apresenta médias bem diferentes quando avaliado entre as regiões do país, entre as quais se destaca a região norte, onde o peixe possui maior influência sobre a base alimentar da população em comparação com as outras regiões $[3,4]$.

A composição química da carne de peixe depende de muitas variáveis, como a espécie; tamanho; estado fisiológico; gênero; habitat e estação do ano, havendo inclusive variações entre indivíduos da mesma espécie. Contudo, seus valores aproximam-se bastante da composição da carne bovina, suína e de aves, sendo a água o principal componente, apresentando percentuais entre 60 e $85 \%$; seguida pelas proteínas, com aproximadamente $20 \%$; e pelos lipídeos, variando entre 0,6 a $36 \%$. Já as cinzas $(1$ a $2 \%)$ e os carboidratos $(0,3$ a $1 \%)$ são os constituintes presentes em menor quantidade [5]. Em relação à qualidade proteica, a carne de peixe contém aminoácidos essenciais, como a lisina e a metionina, sendo, portanto, fundamentais em uma dieta equilibrada [6].

O filé é a maior parte comestível do peixe, proveniente da região dorsal e abdominal do animal. É formado por tecido muscular, tecido conectivo e tecido adiposo, sendo um dos produtos processados de peixe mais procurado nos mercados varejistas $[7,8,9]$.

O peixe é considerado um alimento proteico de fácil deterioração, que exige cuidados e técnicas específicas de conservação e higiene, regidas pela legislação federal, em toda a cadeia produtiva, inclusive na comercialização, para assegurar que o produto chegue com qualidade até o consumidor final. $\mathrm{O}$ beneficiamento e a comercialização de peixes em feiras livres são vistos de forma negativa e extremamente preocupantes, principalmente em relação aos aspectos higiênico-sanitários, que geralmente são precários e favoráveis ao comprometimento da qualidade e da composição desse alimento [10].

Quanto ao filé de peixe, além das condições inadequadas de produção e venda desse produto em feiras, a remoção das características externas do peixe no processo de filetagem prejudica a avaliação de qualidade mais criteriosa do produto final. Confere, assim, um risco a mais para o consumidor devido à susceptibilidade de fraudes e doenças $[11,12]$.

Entre os vários regulamentos que regem a produção e inspeção de produtos de origem animal, o Regulamento de Inspeção Industrial e Sanitária de Produtos de Origem Animal (RIISPOA) é o principal, tendo em vista sua abrangência federal. Legitimado pelo Decreto $\mathrm{n}^{\circ}$ 30.691/1952, prevê normas de inspeção industrial e sanitária ante e post-mortem, recebimento, manipulação, transformação, elaboração e preparo desses produtos. Abrange, ainda, fiscalizações no estabelecimento e no rebanho em cada etapa de criação e produção $[13,14]$.

A forma de comercialização do peixe em feiras geralmente é in natura, compreendendo aquele recém-capturado, submetido à refrigeração (ou não) e adquirido ainda cru [10]. É considerado próprio para o consumo quando apresenta superfície do corpo limpa, olhos transparentes, guelras avermelhadas, ventre roliço, carne firme de cor própria à espécie e cheiro específico [13].

Em Belém, o peixe é um produto que se destaca pela diversidade e riqueza de espécies exploradas, oriundo, principalmente, de sistemas artesanais de suma importância para a 
socioeconomia do Pará, e até mesmo do Brasil. Contudo, os sistemas artesanais, de maior expressividade na região, são regidos por relações de produção e comercialização extremamente complexas e difusas, tanto no meio aquático, quanto no terrestre $[15,16]$.

Tendo em vista o potencial nutritivo dos peixes, o número elevado de espécies comercializadas na região amazônica e a preocupação com as formas de comercialização em feiras livres, a avaliação físico-química e o estudo da composição centesimal, sobretudo ao que se refere à ocorrência de diferenças e semelhanças entre as espécies, pode fornecer informações sobre a qualidade e estimular o consumo de peixes regionais. Em função desse cenário, o objetivo deste estudo foi avaliar a qualidade físico-química dos filés de diferentes espécies de peixes comercializados em feiras livres de Belém e determinar a composição centesimal desses produtos.

\section{MATERIAL E MÉTODOS}

Cerca de $500 \mathrm{~g}$ de filé de 14 amostras de cinco diferentes espécies de peixes: dourada (Brachyplatystoma rousseauxii), filhote (Brachyplatystoma filamentosum), piramutaba (Brachyplatystoma vaillantii), pescada gó (Macrodon ancylodon) e pescada amarela (Cynoscion acoupa) foram adquiridos em feiras livres de Belém, Pará. Foram adquiridos três filés para cada espécie, com exceção da dourada representada por duas amostras.

Devido às condições de comercialização de filés de peixe em feiras livres, no momento da coleta as amostras de dourada, pescada amarela e filhote encontravam-se filetadas, não havendo identificação dos espécimes de quais foram retirados os filés. As amostras de filé da piramutaba e pescada gó foram obtidas após seleção dos espécimes de acordo com a espécie e peso.

A aferição da temperatura foi realizada no momento da coleta das amostras, com auxílio de termômetro infravermelho, em três regiões equidistantes em cada um dos filés (Figura 1). Para a medição, as amostras foram dispostas na bancada do local de comercialização, e depois foi calculada a média aritmética das três medições.

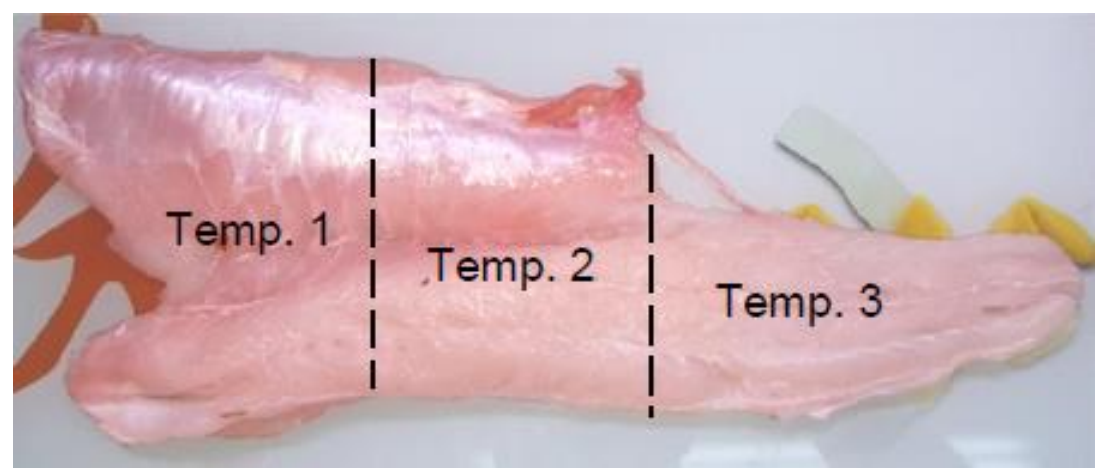

Figura 1: Regiões de aferição da temperatura no filé de peixe.

Posteriormente, as amostras foram colocadas em sacos plásticos, acondicionadas em caixas de poliestireno expandido contendo gelo e transportadas ao Laboratório de Análises de Alimento do Centro de Tecnologia Agropecuária (CTA) da Universidade Federal Rural da Amazônia (Ufra), para a realização das análises físico-químicas e composição centesimal.

No laboratório, as amostras passaram por toalete para retirada de restos de pele, de espinhas, da musculatura escura e de sangue e, em seguida, foram trituradas em multiprocessador. Para as determinações de $\mathrm{pH}$, prova de amônia, umidade, prova de cocção e cinzas, as amostras foram utilizadas imediatamente após o preparo. Para as determinações de proteínas e lipídeos as amostras foram acondicionadas em sacos plásticos com lacre, devidamente identificadas e mantidas na temperatura de $4{ }^{\circ} \mathrm{C}$ por um período de 24 horas até o momento das análises.

Foram realizadas determinações de $\mathrm{pH}$, prova de cocção, prova para amônia, umidade, cinzas, proteínas e lipídeos segundo metodologia proposta pelo Laboratório Nacional de Referência Animal [17]. Além destas análises, avaliou-se também o teor de carboidratos e o 
valor calórico, de acordo com a metodologia utilizada pelo Instituto Adolfo Lutz [18]. Todas as análises foram realizadas em triplicata.

A partir dos resultados das análises físico-químicas e de composição centesimal, foram calculadas as médias e os desvios padrão pelo programa Excel $^{\circledR} 2010$ para cada espécie de peixe.

Posteriormente, com auxílio do software Minitab ${ }^{\circledR} 2010$, versão 16.0 , os valores de média foram submetidos à análise de variância (ANOVA) e teste de Tukey $(\mathrm{p}<0,05)$. Além dessas, a análise de agrupamentos hierárquicos (HCA, do inglês Hierarchical Cluster Analysis) e análise de componentes principais (PCA, do inglês Partial Components Analysis) foram utilizadas para a verificação de semelhanças e agrupamentos entre as médias dos parâmetros de composição centesimal.

\section{RESULTADOS E DISCUSSÃO}

Os resultados das análises de temperatura e $\mathrm{pH}$ dos filés de cinco espécies de peixes comercializadas em feiras livres de Belém estão demonstrados na Tabela 1.

Tabela 1: Temperatura e pH dos filés de peixes avaliados em Belém-PA.

\begin{tabular}{cccc}
\hline & \multicolumn{3}{c}{ Parâmetros } \\
\cline { 2 - 4 } Amostras & Temperatura $\left({ }^{\circ} \mathbf{C}\right)$ & pH & $\begin{array}{c}\text { Prova de } \\
\text { amônia }\end{array}$ \\
\hline Dourada & $14,5^{\mathrm{b}} \pm 0,09$ & $6,70^{\mathrm{b}} \pm 0,06$ & Ausente \\
Filhote & $10,9^{\mathrm{c}} \pm 0,26$ & $6,37^{\mathrm{c}} \pm 0,23$ & Ausente \\
Piramutaba & $16,0^{\mathrm{b}} \pm 0,18$ & $6,89^{\mathrm{b}} \pm 0,06$ & Ausente \\
Pescada gó & $22,7^{\mathrm{a}} \pm 2,23$ & $6,61^{\mathrm{bc}} \pm 0,04$ & Ausente \\
Pescada amarela & $15,0^{\mathrm{b}} \pm 0,81$ & $7,66^{\mathrm{a}} \pm 0,03$ & Ausente \\
\hline
\end{tabular}

Os resultados são apresentados como média \pm desvio padrão. Médias, na mesma coluna, com letras diferentes diferem entre si pelo teste de Tukey $(\mathrm{p}<0,05)$.

Apenas as temperaturas dos filés de pescada gó e filhote apresentaram diferenças significativas $(p<0,05)$. Com os valores de temperatura é possível constatar que todos os filés estavam sendo vendidos em temperatura muito acima do ponto de fusão do gelo preconizado pela legislação [19]. Temperaturas elevadas degradam a carne do peixe e aumentam as chances de contaminação por bactérias e a sua proliferação.

Tendo em vista que cada espécie avaliada foi obtida em feiras distintas, as variações de temperatura observadas podem estar relacionadas às diferentes formas de conservação e exposição do peixe nas feiras. Este armazenamento ocorre sob e sobre o gelo, como relatado em uma pesquisa desenvolvida na mesma região [20] sobre as condições de comercialização de peixes em feiras livres de Belém.

Entre as médias de $\mathrm{pH}$ das amostras, a pescada amarela apresentou diferença significativa $(\mathrm{p}<0,05)$ das outras espécies. Contudo, pelo RIISPOA [13], as amostras apresentaram-se fora dos padrões, pois essa legislação estabelece que o valor de $\mathrm{pH}$ na carne interna dos peixes deva ser de no máximo 6,5. Desta forma, apenas as amostras de filhote podem ser consideradas como produto fresco.

Segundo Kubitza [21], variações de $\mathrm{pH}$ na carne de peixes estão diretamente ligadas à temperatura de armazenamento do produto. Isto pode explicar os valores elevados de $\mathrm{pH}$ observados nesse estudo, uma vez que a manutenção da temperatura de conservação dos filés nas diferentes feiras avaliadas não foi considerada satisfatória.

Quanto aos resultados das provas de cocção e de amônia, todas as amostras apresentaram-se dentro dos padrões estabelecidos na legislação. Se considera para a prova de cocção o odor característico de peixe e a consistência firme da carne. Para a prova de amônia, a ausência dessa substância química. A ausência de amônia indica que os filés estavam em condições adequadas de consumo. 
Mesmo estando em conformidade com a legislação, devido à subjetividade da prova de cocção e ao fato da prova de amônia ser um método qualitativo, os resultados dessas duas análises devem ser utilizados com cautela na determinação do estado de conservação de peixes. Logo, é pertinente a correlação destes resultados com os resultados de análises quantitativas, como a de $\mathrm{pH}$, sem negligenciar as análises sensoriais para a determinação da qualidade do peixe $[14,22]$.

Na Tabela 2 são apresentados os resultados da composição centesimal das amostras de filés de peixe.

Tabela 2: Composição centesimal dos filés das cinco espécies de peixe (valores expressos em base úmida).

\begin{tabular}{cccccc}
\hline Parâmetros & Dourada & Filhote & Piramutaba & $\begin{array}{c}\text { Pescada } \\
\text { gó }\end{array}$ & $\begin{array}{c}\text { Pescada } \\
\text { amarela }\end{array}$ \\
\hline Umidade (\%) & $82,49^{\mathrm{b}} \pm$ & $79,53^{\mathrm{c}} \pm$ & $81,11^{\mathrm{bc}} \pm$ & $78,80^{\mathrm{c}} \pm$ & $85,45^{\mathrm{a}} \pm$ \\
& 0,05 & 1,88 & 0,44 & 0,54 & 1,04 \\
Proteínas (\%) & $15,90^{\mathrm{b}} \pm$ & $17,06^{\mathrm{ab}}$ & $17,70^{\mathrm{ab}} \pm$ & $18,63^{\mathrm{a}} \pm$ & $13,83^{\mathrm{c}} \pm$ \\
& 0,46 & $\pm 1,23$ & 0,24 & 0,40 & 0,80 \\
Lipídios (\%) & $0,08^{\mathrm{a}} \pm$ & $1,44^{\mathrm{a}} \pm$ & $0,08^{\mathrm{a}} \pm$ & $0,74^{\mathrm{a}} \pm$ & $0,08^{\mathrm{a}} \pm$ \\
& 0,09 & 1,57 & 0,04 & 0,54 & 0,05 \\
Cinzas (\%) & $1,33^{\mathrm{ab}} \pm$ & $1,02^{\mathrm{b}} \pm$ & $1,52^{\mathrm{a}} \pm$ & $0,98^{\mathrm{b}} \pm$ & $1,18^{\mathrm{ab}} \pm$ \\
& 0,29 & 0,22 & 0,25 & 0,07 & 0,11 \\
Carboidratos (\%) & $0,21 \pm$ & $0,95 \pm$ & $\mathrm{ND}$ & $0,84 \pm 0,47$ & $\mathrm{ND}$ \\
Valor calórico & 0,61 & 0,78 & & & \\
(kcal/100g) & $65,80 \pm$ & $85,03 \pm$ & $71,55 \pm$ & $84,58 \pm$ & $56,04 \pm$ \\
\hline
\end{tabular}

$\mathrm{ND}$ - não detectado. Médias na mesma linha com letras diferentes diferem entre si pelo teste de Tukey $(\mathrm{p}<0,05)$.

De forma geral, pode-se observar que houve diferença significativa $(\mathrm{p}<0,05)$ entre as espécies nos componentes analisados (umidade, proteínas e cinzas). Este resultado demonstra a influência do fator espécie na composição química da carne, como mencionado por vários autores [5, 23, 24, 25]. Em relação aos lipídeos, os percentuais médios das espécies não diferiram estatisticamente ( $>>0,05)$, o que sugere uma distribuição homogênea do teor de lipídeos nos filés das diferentes espécies analisadas. Na avaliação de umidade, a pescada gó foi a espécie que apresentou o menor percentual de umidade, e a pescada amarelada o maior percentual. Com o teste de comparação das médias é possível observar diferença estatística entre os valores de umidade de dourada, pescada amarela e pescada gó/filhote. Somente as amostras de piramutaba apresentaram valores de umidade intermediários entre espécies de peixes (dourada e pescada gó/filhote). De forma geral, todas as amostras apresentam elevado conteúdo de água na sua constituição. Destaca-se que o percentual de umidade da pescada amarela observada nesse estudo mostrou-se acima dos 79,82 \% obtidos em amostras da mesma espécie na cidade de Belém - PA [26]. Quanto às proteínas, as espécies pescada gó, dourada e pescada amarela diferiram significativamente $(p<0,05)$. As amostras de filhote e piramutaba apresentaram somente diferença com os valores obtidos para pesca amarela. A pescada amarela foi a espécie que apresentou resultado significativo de menor teor proteico. Em relação ao intervalo formado entre o menor e o maior percentual, os valores são coerentes com os encontrados em outro trabalho [23]. Não houve diferença estatística entre as espécies em relação à quantidade de lipídeos. De todo modo, os valores médios obtidos em cada espécie permitem classificar os filés desse estudo como magros devido aos teores de lipídeos encontrados estarem abaixo de $5 \%$ [25, 27]. Os resultados de cinzas mostraram que houve diferença estatística entre as amostras de filhote/pescada gó e piramutaba. O intervalo geral observado nos teores de cinzas ocorreu entre 0,98 e $1,52 \%$ e, estes encontram-se próximos aos valores de 1 a $2 \%$ referidos na literatura específica [5]. A determinação de cinzas fornece uma indicação da riqueza da amostra em elementos minerais. Segundo Contreras-Guzmán (1994) [28], peixes de água doce apresentam variações na fração de cinzas que vão de $0,99 \%$ a $3,39 \%$, variação que 
também está compatível com os resultados observados nas espécies de peixes avaliadas. Os carboidratos variaram na faixa de 0,21 a $0,95 \%$ e apresentaram médias compatíveis com as observadas em outro trabalho [5]. A não detecção de carboidratos nas amostras de piramutaba e pescada amarela pode ser explicada pelo baixo teor desse componente em peixes relatado por vários autores [5, 23, 24]. Além disso, ao comparar-se o número de amostras sem quantificação de carboidrato e o número de amostras que apresentaram valor de $\mathrm{pH}$ considerado elevado para o produto, é possível inferir a ocorrência de estresse pré-abate, uma vez que o valor de $\mathrm{pH}$ da carne de peixe tem relação direta com a reserva energética do animal antes e após o abate [21, $29,30]$. Devido o percentual de carboidrato ter sido obtido por diferença, este não foi aplicado à análise estatística de comparação entre as médias. Entretanto, estes dados foram usados no cálculo do valor calórico das amostras.

O valor calórico médio das espécies apresentou variações de 56 a $85 \mathrm{kcal} / 100 \mathrm{~g}$. O intervalo confirma o fato de que os peixes são considerados alimentos de baixo valor calórico, principalmente quando comparados aos valores de outros alimentos de origem animal, como lombo de porco $(212 \mathrm{kcal} / 100 \mathrm{~g})$, contrafilé bovino $(192 \mathrm{kcal} / 100 \mathrm{~g})$, coxa de frango (156 $\mathrm{kcal} / 100 \mathrm{~g}$ ), ovo de galinha (146 kcal/100 g) e ovo de codorna (135 kcal/100 g) [31].

Os resultados da HCA e PCA foram obtidos utilizando os parâmetros de umidade, proteínas, cinzas e lipídeos da composição centesimal. Os dados de carboidratos não foram incluídos por não terem sido detectados nas amostras de piramutaba e pescada amarela.

No gráfico gerado pela HCA, apresentado na Figura 2, pode-se observar que houve a formação de dois grandes grupos. O primeiro formado por amostras de dourada (D), filhote (F), piramutaba (Pi) e pescada amarela (PA), e o segundo formado por amostras de filhote (F) e pescada gó $(\mathrm{G})$. A similaridade apresentada entre esses dois grupos foi igual à zero.

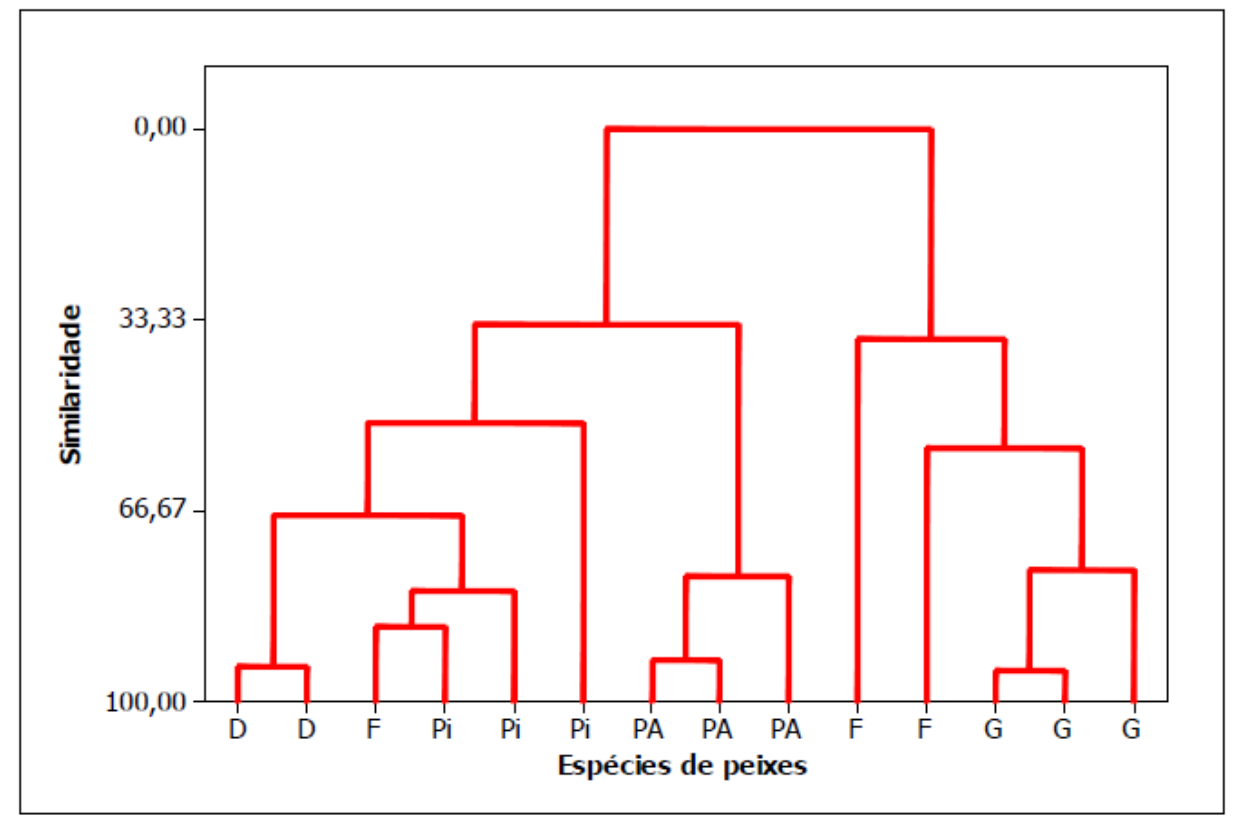

Figura 2: Gráfico correspondente à HCA da composição centesimal dos filés de peixe.

Ao avaliar a similaridade acima de $66,67 \%$ pode-se notar que as amostras de dourada, pescada amarela e pescada gó apresentaram agrupamento de acordo com suas respectivas espécies, apesar de as amostras de pescada gó não possuírem nenhuma similaridade com o grupo da dourada e da pescada amarela. Quanto a piramutaba (Pi), mesmo uma das amostras apresentando menor similaridade (abaixo de 66,67 \%) em relação às outras duas, o agrupamento dessa espécie é perceptível. Entretanto, as principais disparidades ocorreram entre as três amostras de filhote. Duas dessas amostras apresentaram similaridade próxima de 33,33\%. A terceira amostra de filhote não apresentou nenhuma similaridade com as outras amostras dessa mesma espécie, mas demonstrou similaridade acima de 33,33\% e 66,67 \% com as amostras de piramutaba. 
A análise de agrupamento hierárquico representa um processo gradativo no qual a matriz de dados apontou a reunião das amostras semelhantes de filés de peixes por espécie. O próprio objetivo da HCA é mostrar os dados em um espaço bidimensional e que demonstre os agrupamentos e padrões naturais esperados.

Já no gráfico da PCA (Figura 3), com 86,5 \% de representatividade, de acordo com a soma dos percentuais do componente primário $(58,9 \%)$ e secundário $(27,6 \%)$, pode-se perceber novamente a formação de quatro grupos, cada um representado por amostras de espécies diferentes (pescada amarela, dourada, piramutaba e pescada gó). Devido às diferenças apresentadas entre os dados das amostras de filhote, o agrupamento dessa espécie não ocorreu, corroborando os dados observados no gráfico da HCA.

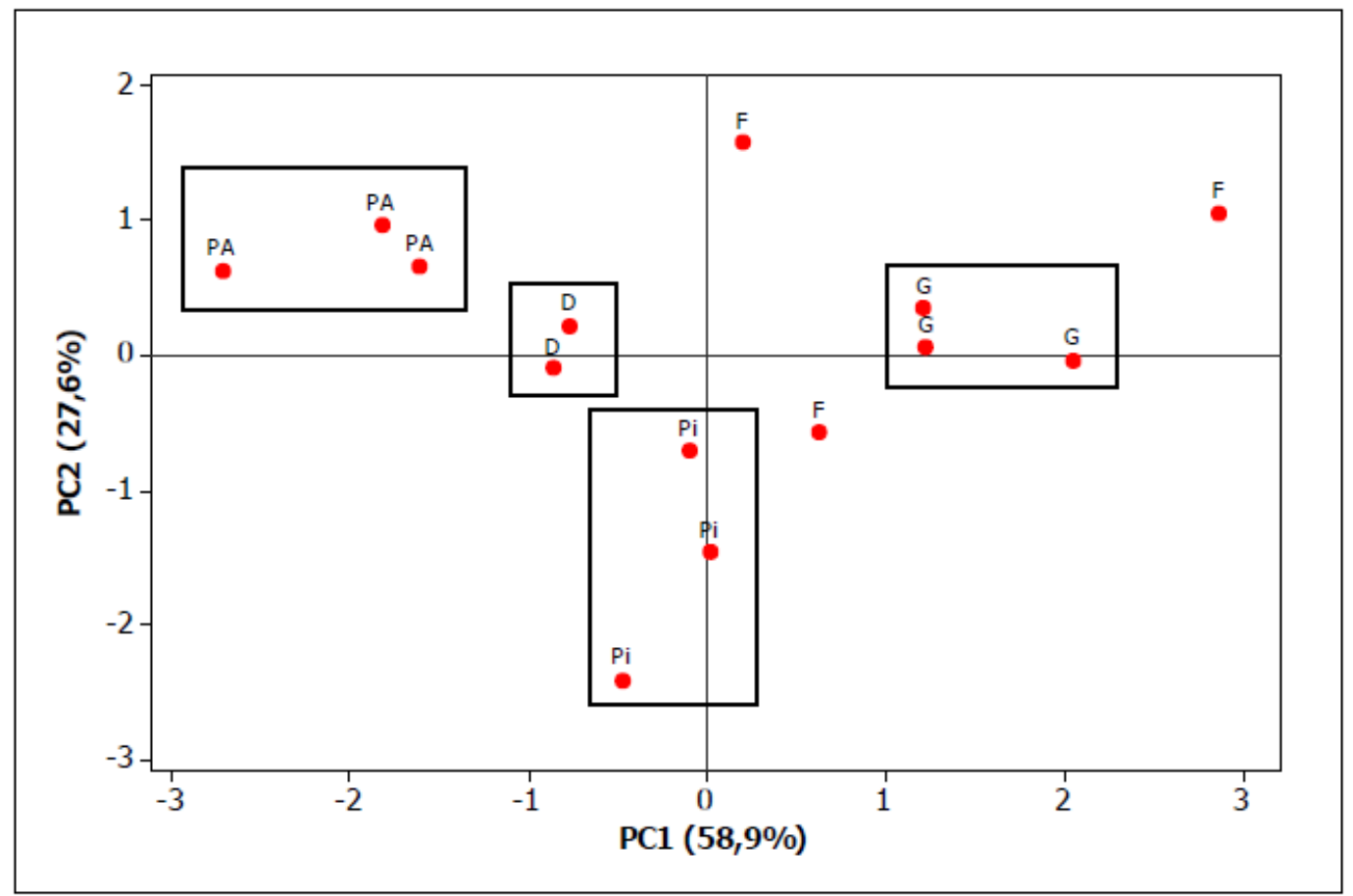

Figura 3: Gráfico representativo da PCA das amostras de filé de peixe.

Analisando a PC1 é possível observar a discriminação de quatro grupos, ou seja, as amostras provenientes da pescada amarela (PA), da dourada (D), da piramutaba (Pi) e da Pescada gó (G). É possível observar um ligeiro afastamento entre as amostras dentro do grupo formado entre filés de pescada amarela e entre o grupo de amostras de filé de pescada gó. Através da análise da PC2 é possível observar um ligeiro afastamento entre as amostras dentro do grupo de filés de piramutaba. Um grupo entre as amostras de filhote somente seria formado entre duas amostras, seja pela observação através da PC1 ou da PC2. Em ambos os casos, as amostras apresentam um afastamento acentuado entre as três amostras.

De forma geral, quatro das cinco espécies de peixes avaliadas apresentaram semelhanças estatísticas entre suas respectivas amostras, formando grupos, demonstrando que a composição centesimal dos filés de peixes analisados neste trabalho foi influenciada pela espécie. Essa avaliação diverge do encontrado por outros autores [5, 23], os quais mencionam que por não haver um padrão, a composição centesimal de peixes não permite classificá-los de acordo com a espécie.

Quanto às amostras de filhote, a julgar pelas diferenças apresentadas entre si e o maior grau de afinidade de uma dessas amostras com as da piramutaba, além do valor comercial e das características morfológicas corporais dessas espécies, é possível inferir a possível ocorrência de fraude por adulteração. A provável comercialização de uma espécie de menor valor ou maior disponibilidade por outra com maior interesse comercial é uma prática abusiva, desenvolvida principalmente em comércios varejistas, como as feiras livres [32]. 
Essa possível fraude poderia ser evitada se os comércios varejistas seguissem o que preconiza o RIISPOA [13] ou a portaria 185/97 do Ministério da Agricultura, Pecuária e do Abastecimento [1], de que os produtos de origem animal expostos à venda devem estar identificados por meio de rótulos registrados para evitar erros, confusões ou fraudes.

\section{CONCLUSÃO}

A temperatura das amostras de filé de peixe analisadas estavam acima do limite máximo estabelecido na legislação brasileira para peixe fresco. Das cinco espécies avaliadas, apenas uma obteve valor de $\mathrm{pH}$ dentro do limite preconizado na legislação brasileira e as amostras atendiam aos padrões de conformidade quanto as provas de cocção e amônia.

A composição centesimal do produto apresentou variações coerentes com as mencionadas na literatura, revelando baixo teor de gordura e de valor calórico, podendo ser considerado um produto magro.

Nas avaliações de semelhanças e agrupamentos da HCA e PCA, as espécies de peixes foram separadas conforme suas características físico-químicas, com exceção das amostras de filhote.

A prática de filetagem prévia e a venda do produto sem qualquer informação segura, que comprove sua procedência, podem ser bastante prejudiciais para o consumidor, devido à falta de meios precisos que identifique o filé de peixe comercializado de acordo com a espécie.

\section{AGRADECIMENTOS}

Os autores agradecem a Universidade Federal Rural da Amazônia e ao Centro de Tecnologia Agropecuária.

\section{REFERÊNCIAS BIBLIOGRÁFICAS}

1. BRASIL. Ministério da Agricultura, Pecuária e do Abastecimento. Portaria $\mathrm{n}^{\circ} 185$, de 13 de maio de 1997. Dispõe sobre o Regulamento Técnico de Identidade e Qualidade de Peixe Fresco (Inteiro e Eviscerado). Disponível em http://www.defesa.agricultura.sp.gov.br/www/legislacoes/popup.php?action=view\&idleg=670 Acesso em: 10 abr 2016.

2. FAO - Food and Agriculture Organization of the United Nations. The State of Fisheries and Aquaculture. Rome: Italy; 2014. 223 p.

3. Goes GA, Oliva RA, Ronqui RG, Queiroz TR, Satolo EG. Descrição do sistema logístico de transporte: uma análise conceitual envolvendo piscicultura. South American Development Society Journal. 2005 Mai/Ago;1(2):100-115.

4. Souza AM, Pereira RA, Yokoo EM, Levy RB, Sichieri R. Alimentos mais consumidos no Brasil: Inquérito Nacional de Alimentação 2008-2009. Revista Saúde Pública. 2013 Fev;47(1): 190-199, doi: 10.1590/S0034-89102013000700005.

5. Ogawa M, Maia EL. Manual da pesca , ciência e tecnologia do pescado. São Paulo: Varela; 1999. 430 p.

6. Oetterer M, d'Arce MABR, Spoto M. Fundamentos de ciência e tecnologia de alimentos. Piracicaba: Editora Manole; 2006. 632 p.

7. Souza MLR. Comparação de seis métodos de filetagem, em relação ao rendimento de filé e de subprodutos do processamento da tilápia-do-Nilo (Oreochromis niloticus). Revista Brasileira de Zootecnia. 2002 Mai/Jun.31(3):1076-1084, doi: 10.1590/S1516-35982002000500003.

8. Barbosa JA, Santana AC, da Silva IM, Botelho MN, Condurú Neto JMH. Características comportamentais do consumidor de peixe no mercado de Belém. Boletim Técnico Científico do Cepnor/Tropical Journal of Fisheries and Aquatic Sciences. 2007 Jan/Dez.7(1):115-133.

9. Dutra FM, Binotto E, Mauad JRC. Uma análise do comportamento do consumidor de peixe em Dourados/MS. Revista Sociedade e Desenvolvimento Rural. 2014 Ago.8(2):84-100.

10. Silva ML, Matté GR, Matté MH. Aspectos sanitários da comercialização de pescado em feiras livres da cidade de São Paulo, SP/Brasil. Revista do Instituto Adolfo Lutz. 2008 Set/Dez.67(3):208-214. 
11. Santos RD, Gagliardi ACM, Xavier HT, Magnoni CD, Cassani R. et al. I Diretriz sobre o consumo de Gorduras e Saúde Cardiovascular. Arquivos Brasileiros de Cardiologia. 2013 Jan.100(1):1-40.

12. Fernandes CE. Valor nutricional e perfil lipídico das espécies de peixes: cavala (Scomberomorus cavalla), agulha-branca (Hemiramphus brasiliensis), agulha-preta (Hyporhamphus unifasciatus) e sardinha-laje (Opisthonema oglinum). Recife (PE): Universidade Federal de Pernambuco; 2014. 76p.

13. BRASIL. Ministério da Agricultura. Regulamento da Inspeção Industrial e Sanitária de Produtos de Origem Animal (RIISPOA). Decreto $\mathrm{n}^{\circ} 30.691$ de 29 de março de 1952, alterado pelos decretos $\mathrm{n}^{\circ}$ 1.255 de 25 de julho de $1962, \mathrm{n}^{\circ} 1236$ de 02 de setembro de $1994, \mathrm{n}^{\circ} 1812$ de 18 de fevereiro de 1996, n 2244 de 04 de junho de 1997. Dispõe sobre o novo Regulamento da Inspeção Industrial e Sanitária de Produtos de Origem Animal - R.I.I.S.P.O.A. Disponível em: http://www.planalto.gov.br/ccivil_03/decreto/1950-1969/D30691.htm. Acesso em: 10 abr 2016.

14. Martins CN. Parâmetros de qualidade e valoração de pescada da espécie Macrodon ancylodon (Bloch \& Schneider, 1801): características sensoriais, físico-químicas, microbiológicas, parasitológicas e contaminantes inorgânicos. São Paulo (SP): Universidade de São Paulo; 2011. 197 p.

15. Silva ESC, da Cunha DS, de Araújo CSP, Sales AD, Holanda FCAF. Cadeia de comercialização do pescado desembarcado no posto fiscal de Bragança, Estado do Pará. Arquivos de Ciência do Mar. 2012 Jan/Jun.45(1):82-87.

16. da Silva LJD, Rodrigues CI. Redes sociais e práticas culturais locais na distribuição do pescado no Ver-o-Peso para a porção continental da cidade de Belém-Pará. Anais: Encontros Nacionais da ANPUR. 2013 Jan.15(1):1-16.

17. BRASIL - Ministério da Agricultura, Secretaria Nacional de Defesa Agropecuária. Métodos analíticos oficiais para controle de produtos de origem animal e seus ingredientes: II - Métodos físicos e químicos. Brasília: Laboratório Nacional de Referência Animal; 1981.122 p.

18. IAL - Instituto Adolfo Lutz. Métodos físico - químicos para análise de alimentos. São Paulo: Governo de São Paulo; 2005. 1000 p.

19. BRASIL. Ministério da Saúde. Agência Nacional de Vigilância Sanitária. Portaria no 326, de 30 de julho de 1997. Dispõe sobre o Regulamento técnico sobre as condições higiênico-sanitárias e boas práticas de fabricação para estabelecimentos produtores/industrializadores de alimentos. Disponível em: $\quad$ http://portal.anvisa.gov.br/documents/33916/388704/Portaria\%2BSVSMS\%2BN.\%2B326\%2Bde\%2B30\%2Bde\%2BJulho\%2Bde\%2B1997.pdf/87a1ab03-0650-4e67-9f3159d8be3de167. Acesso em: 10 abr 2016.

20. Lima CLS. Avaliação dos perigos microbiológicos em uma indústria de beneficiamento de pescados e sugestão de um sistema de gestão de qualidade. Belém (PA): Universidade Federal do Pará; 2012. 127 p.

21. Kubitza F. "Off-flavor", Nutrição, Manejo Alimentar e Manuseio Pré-Abate Afetam a Qualidade do Peixe Destinado à Mesa. Panorama da Aquicultura. 1999 Jul/Ago.9(54):39-49.

22. de Almeida NM, Kodaira M, Batista GM, Lessi E. Alterações post-mortem em tambaqui (Colossoma macropomum) conservados em gelo. Ciência Rural. 2006 Jul/Ago.36(4):1288-1293, doi: 10.1590/S0103-84782006000400038.

23. Badolato ES, Carvalho JB, Amaral Mello MRP, Tavares M, Campos NC, Aued-Pimentel S, Morais C. Composição centesimal, de ácidos graxos e valor calórico de cinco espécies de peixes marinhos nas diferentes estações do ano. Revista do Instituto Adolfo Lutz. 1994 Jan.54(1):27-35.

24. Oetterer M. Tecnologia do pescado - da adoção de técnicas de beneficiamento e conservação do pescado de água doce. Piracicaba: ESALQ/USP; 2003. 13 p.

25. Ordóñez JÁ, Rodriguez MIC, Sanz MLG, Minguillón GDGF, Perales LH, Cortecero MDS. Tecnologia de Alimentos: alimentos de origem animal. Porto Alegre: Artmed; 2005. 41 p.

26. de Souza HAL, Bentes AS, Simões MG, Fontelles MJP. Caracterização física e nutricional de três espécies de peixes amazônicos. Revista Brasileira de Tecnologia Agroindustrial. 2010 Jul. 4(2):141152, doi: 10.3895/S1981-36862010000200003.

27. Penfield MP, Campbell AM. Experimental food science. San Diego: Academic Press; 1990. 540 p.

28. Contreras-Guzmán ES. Bioquímica de pescados e derivados. Jaboticabal: FUNEP; 1994. 409 p.

29. Lins ASR, de Carvalho VT, Lafisca A, Viana AC. Qualidade do Carí em feiras na cidade de PetrolinaPE. Vigilância Sanitária em Debate: Sociedade, Ciência \& Tecnologia. 2015 Mai.3(2):108-113, doi: 10.3395/2317-269x.00322.

30. Vargas SC. Influência de diferentes métodos de insensibilização pré-abate sobre parâmetros físicos, químicos e sensoriais da carne refrigerada e congelada de bijupirá (Rachycentron canadum). São Paulo (SP): Universidade de São Paulo; 2015.98 p.

31. Torres EAFS, Campos NC, Duarte M, Garbelotti ML, Philippi ST, Rodrigues RSM. Composição centesimal e valor calórico de alimentos de origem animal. Ciência e Tecnologia de Alimentos. 2000 Mai/Ago.20(2):145-150, doi: 10.1590/S0101-20612000000200003. 
32. Neto DAP. Detecção de adulteração de espécies em pescado e derivados por meio da técnica de DNA Barcoding. Belo Horizonte (MG): Universidade Federal de Minas Gerais; 2013. 43 p. 